\title{
L. Contributions to the theory of luminous flames
}

\section{Dr. Karl Heumann}

To cite this article: Dr. Karl Heumann (1877) L. Contributions to the theory of luminous flames, Philosophical Magazine Series 5, 3:19, 366-382, DOI: 10.1080/14786447708639252

To link to this article: http://dx.doi.org/10.1080/14786447708639252

$$
\text { 曲 Published online: } 27 \text { Jul } 2009 .
$$

Submit your article to this journal

Џ Article views: 2

Q View related articles $₫$ 
out, taxed the vast analytic power of Euler himself. In two different memoirs* it is a subject of inquiry with him ; and in one place $\dagger$ he says that he had spent much labour upon it, but that the harder it seemed the more advantage did he hope to draw from the solution. And yet Wallis's theorem is, as we have seen, one of the simplest cases of the general result here established with comparative ease.

Glasgow, February 6, 1877.

\section{Contributions to the Theory of Luminous Flames.} By Dr. Karl Heumann $\ddagger$.

[Plate II.]

[Concluded from p. 107.]

$\mathrm{I}^{\mathrm{N}}$ a former part of these papers I have declared my belief in the view which regards the separation of solid carbon as the cause of the luminosity of the flame produced by burning hydrocarbonaceous bodies. I have now to prove experimentally the justice of this belief, and to demonstrate the existence of free carbon in such flames.

The increase in the "light-effect" of a gas-flame occasioned by heating the burner-tube has been already traced to the increase in the intensity of light of the flame-mantle, and to the simultaneous enlargement of the flame itself. The increase in intensity of the light may be itself traced either to the higher temperature to which the carbon particles are raised, or to the production of a greater number of such particles in a given volume of the flame-mantle. In either case more light will be emitted by any special portion of the flame. Whether both causes are at work when the burner-tube is heated must remain meanwhile undecided. The increase in size of the flamemantle, noticed when the burner-tube is heated, has been referred to an earlier separation of carbon in the flame, this separation becoming possible by reason of the high temperature to which the gas has been raised.

If this explanation be the true one, it is manifest that any agent, other than heat, capable of producing a separation of carbon in the comparatively cold lower portions of the flame, should also be capable of producing an increase in the size of the flame-mantle. Chlorine and bromine are known to be

* "De Fractionibus Continuis Observationes," Comment. Acad. Fetropol. vol. xi. 1739, pp. 32-81; "De Fractionibus Oontinuis Wallisii," Mémoires de l'Acad. de St. Fétershurg, vol. v. 1815, pp. 24-44.

$\dagger$ Comment. Acad. Petropol. 1739, p. 41.

I Translated, and somew hat condensed, from Liebig s Annalen, vol. clxxxiv. pp. 206-254, by M. M. Pattison Muir. 
capable of producing the former action; and experiment shows that they can also produce the latter*.

Coal-gas issuing from a rather narrow horizontal tube was ignited ; the flame was separated by a space of 1 or 2 centims. from the orifice of the tube. A tube from which chlorine issued was introduced between the burner and the flame: the luminosity of the latter was at once increased; and the flame at the same time extended itself backwards to the point at which the chlorine entered. The volume of the flame-mantle was thus increased at the expense of the blue zone of the flame.

If bromine be employed in place of chlorine, a sooty flame is produced; this is to be traced to the formation of a gaseous compound of bromine and carbon, and consequent partial cutting off of the supply of oxygen.

Before deducing a wide generalization, it seemed to me necessary to inquire whether in every case introduction of cllorine brought about the result theoretically foretold.

The flame of a hydrocarbon may become feebly luminous (1) when the flame-mantle contains a small numler of solid carbon particles. This condition is fulfilled in the flame of all substances relatively poor in carbon-for instance, in the flime of ordinary coal-gas. Such flames are rendered more luminous by addition of chlorine or bromine either before or after the gas is ignited. If chlorine be added before ignition, a partial combustion takes place in the innermost portions of the flame; part of the hydrogen unites with the chlorine, while carbon is set free in solid form and renders luminous the hydrochloric-acid flame within the main flame. Combustion of carbon, and of the hydrogen which is uncombined with chlorine proceeds at the outer part of the flame; inasmuch, however, as the outer portions are comparatively poor in hydrogen but rich in carbon, it follows that an increase in luminosity must take place at these points also.

If chlorine be conducted into the centre of a somewhat large coal-gas flame, two flames are easily distinguishable. If chlorine be mixed with the outer atmosphere in which combustion is taking place, it partially replaces not only the inert nitrogen, but also the oxygen, combining at the same time with bydrogen, but not at all, or only to a very limited extent, with carbon. The latter is therefore partially deposited as soot.

Gases containing little carbon may therefore be caused to burn with a feebly luminous flame by mixing with them substances which at a high temperature partially or completely

* Berzelius showed that the flame of alcohol is rendered luminous by the introduction of chlorine. See Gmelin-Kraut's 'Ilandbook,' i. pt. 2, p. $13 ; 6$ th ed. 
combine with the hydrogen present, and so produce a hydrocarbon rich in carbon, or set free pure carbon itself.

The substitution-products of marsh-gas, $\mathrm{CH}_{3} \mathrm{Cl}$ and $\mathrm{CHCl}_{3}$, are gases fulfilling these conditions. While marsh-gas burns with a feebly luminous flame, the flame of methyl chloride $\left(\mathrm{CH}_{3} \mathrm{Cl}\right)$ is smoky and strongly luminous. Chloroform $\left(\mathrm{CH} \mathrm{Cl}_{3}\right.$ ) also burns at the surface of a wick with a luminous flame. Hydrogen containing a little chloroform vapour burns with a brilliant although non-smoky flame; if a large quantity of chloroform be present, the flame becomes somewhat opaque and deposits much soot. In each of these cases hydrochloric acid is produced.

The flame of a hydrocarbon may become feebly luminous, or even non-luminous when (2) the temperature is not sufficiently high to cause separation of solid carbon. Two cases here present themselves. A low temperature may be occasioned by withdrawal of heat by extraneous causes, as when a luminous flame is brought into contact with cold substances, or by the action of admixed gases which absorb heat, and so reduce the original temperature of the flame. These flames may be so hot as to cause to glow a piece of platinum wire held within them, and yet not hot enough to bring about a deposition of carbon from the hydrocarbonaceous material of the gas. On the supposition already put forward, chlorine ought in either case to render the non-luminous flame luminous.

A small luminous flame was rendered non-luminous by causing it to play upon a porcelain basin. (I have already shown that withdrawal of heat is here the cause of non-luminosity.) So soon as chlorine or bromine vapour was brought into the blue flame, it became luminous and deposited soot upon the basin. This experiment proves that the flame became non-luminous because the temperature was not attained at which carbon is deposited, and that so soon as carbon was separated, even by other means than increase of temperature, luminosity returned.

The blue flame of mixed coal-gas and carbon dioxide, coalgas and air, or coal-gas and carbon monoxide, when mixed with a little chlorine became very luminous ; this was especially noticeable with the flame of mixed coal-gas and air, because this flame is possessed of a higher temperature than the others; and I have already shown that the temperature at which deposition of carbon takes place in flames admixed with indifferent gases is higher than that at which the same phenomenon occurs in the case of flames not so admixed.

The luminosity of a hydrocarbon flame may be diminished (3) by the temperature not being sufficiently high to maintain 
the separated carbon in such a condition as that it shall emit light. Such flames (the flame of turpentine for instance) become luminous when their temperature is increased; this may be done by admitting air or oxygen. The admission of chlorine to such flames may be shown experimentally to have no effect in increasing luminosity.

Frankland has put forward the suggestion that the soot deposited from luminous flames does not consist of carbon, but of a mixture of heavy hydrocarbons whose vapours have been condensed upon the cold body introduced within the flame. Stein * has pointed out that in this case increase of temperature should cause the soot to again assume the gaseous form; experiment proves that this is not so. The absorptive power of carbon for gases seems to me to explain the fact that the soot deposited from luminous flames does not consist of pure carbon. Stein's analyses show 99.1 per cent. of carbon and 0.9 per cent. of hydrogen. I have shown that admission of chlorine to flames containing decomposable hydrocarbons causes an increase in the luminosity of these flames, and that this increase is attended with deposition of soot. Can it be supposed that this soot consists of condensed heavy hydrocarbons? Frankland has himself told us that to obtain pure carbon from the soot deposited from luminous flames it is necessary to heat the deposit in chlorine. If chlorine be then capable of decomposing hydrocarbons at a red heat with production of pure carbon, it can scarcely be the means of bringing about the formation of heary hydrocarbons in the flame itself. In the case of flames rendered luminous by admission of chlorine, free carbon is evidently separated ; and as the phenomena attending the luminosity of flames of high temperature present no points of difference from the same phenomena in the case of flames containing chlorine, the conclusion is that in the high-temperature flumes free carbon is also separated.

It has been already shown that when a porcelain rod is held in a gas-flame, the lower surface (that is, the surface opposed to the stream of burning gas) is alone at first covered with soot, and that a thin film of soot is formed on the upper surface only after the expiry of a considerable time.

This experiment affords direct proof of the presence of solid carbon particles in the luminous flame. If the action of the cold object were to condense the rapours of hydrocarbons, such condensation would of course take place equally around the cold object; but the facts of the experiment show that the deposition is a purely mechanical operation exactly comparable with the deposition of dust upon the walls of a room.

* Journ. Pract. Chem. (N. S.) vol. viii. p. 402.

Phil. Mag. S. 5. Vol. 3. No. 19. May 1877. 
Further, the fact experimentally proved, that the surface of a body heated to redness may become covered with soot, is opposed to Frankland's hypothesis : if the deposition consisted of condensed hydrocarbons, it could only take place upon surfaces relatively colder than the flame itself. If the space immediately over the flame of burning turpentine be examined, it is seen to contain flaky particles of sooty matter. A hydrogenflame brought into this layer becomes surrounded by a continuous luminous mantle; the flame of a Bunsen lamp becomes crowded with glowing particles. No glowing particles can be distinguished by the eye or by means of the microscope in a luminous gas-flame, by reason of the rapidity with which the current of gas is carried upwards. These small particles are stopped in their upward course by any solid body brought into the flame, or by the comparatively still layers of air; they thus become more compact and dense, and so bring about the deposition upon themselves of further numbers of particles antil there is finally formed a visible cloud of soot or smoke. A solid body, or even a layer of air, while stopping the rush of solid particles, simultaneously lowers the temperature of the flame.

In order to render visible the production of masses of solid matter, two blowpipe-nozzles, through each of which a stream of gas issued, were arranged horizontally opposite to one another. By regulating the distance between the nozzles a perfectly circular homogeneous flame was obtained; by bringing the nozzles rather nearer to one another and slightly altering their inclination, the flame assumed a half-moon shape. The lower part of this flame was but slightly luminous, but was filled with little glowing points (fig. 1, Plate II.). The flame being in a kind of whirling motion, these little points were swept upwards and passed away as sparks from each horn of the half-moon. By bringing a porcelain plate over these points, the little particles were obtained in the form of coarsegrained soot. The appearances described become more apparent by causing the gas to issue under diminished pressure; but in this case the regulation of the flow is more difficult.

Another experiment was arranged in which the little particles of carbon were caused to form a larger and visible mass by projection against a solid body. A platinum basin hung vertically was heated on the concave side by means of a Bunsen's lamp; a coal-gas flame about 5 centims. in length was caused to issue from the narrow circular orifice of a tube which was held by a clamp, and directed so that the flame struck the basin a little below the centre. By regulating the distance between this tube and the basin, a halfmoon-sbaped flame 
Phil. Mag. S. 5.Vol.3. PI.I.

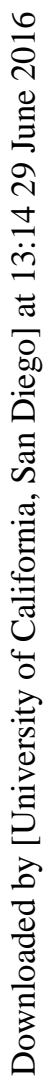
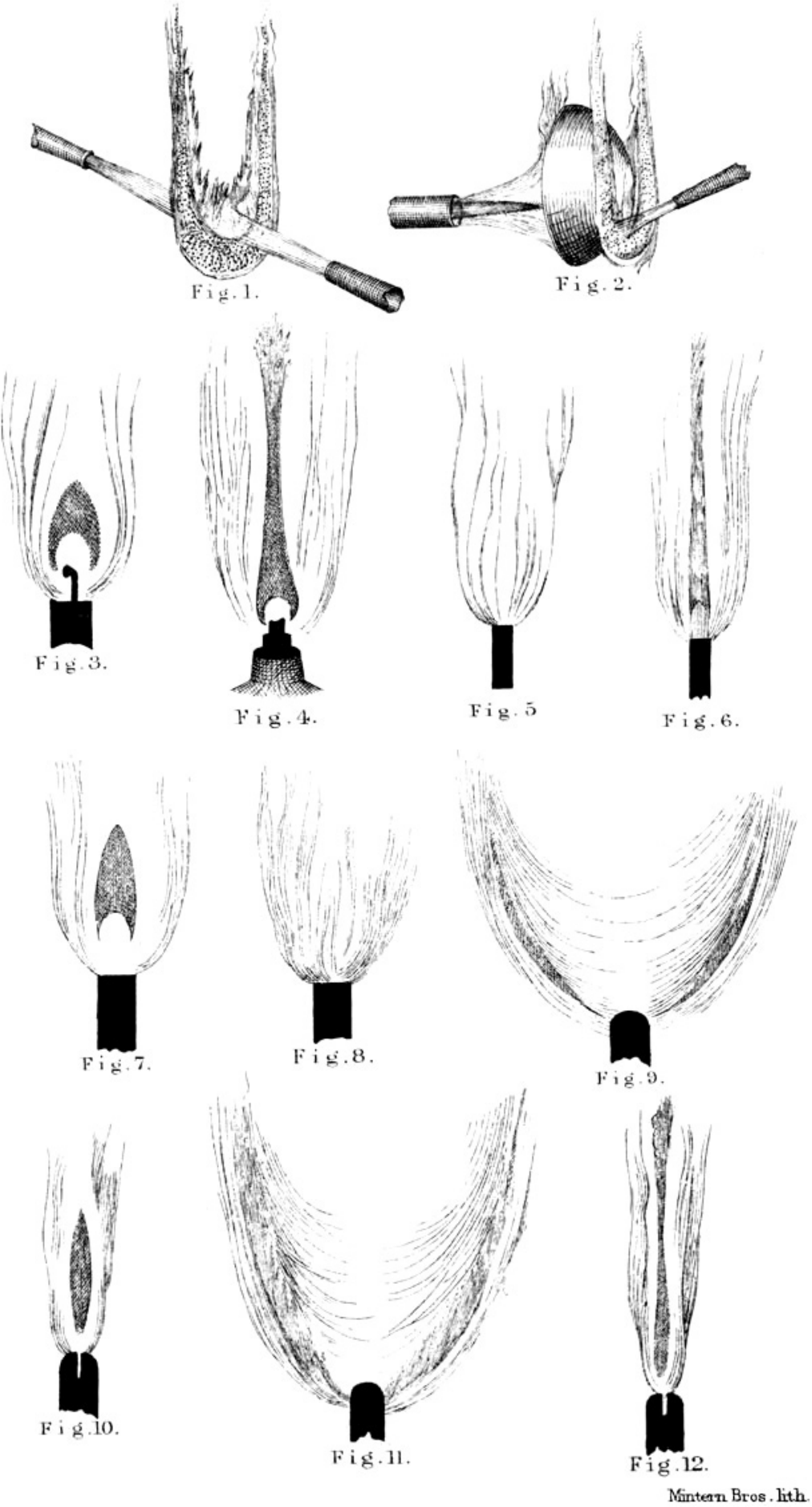

F is. 6 . 
was obtained crowded with little glowing particles which ascended with a spiral motion, escaping from each horn of the half-moon (fig. 2). The separation of solid carbon within a coal-gas flame is thus rendered visible to the eye. The experiment further shows that in an ordinary coal-gas flame the solid particles are very small but numerous, and that, when a number of these are gathered together in a special part of the flame, that part becomes continuously luminous.

Frankland looks upon the fact of the transparency of luminous flames as militating against the view that they contain solid particles. We know, however, that many substances containing solid matter (for instance, paper soaked in oil) are more or less transparent. Stein has also shown that it is very difficult to distinguish ordinary letters placed behind a gasflame consisting of several layers, or behind the flame of a petroleum lamp. My own experiments confirm those of Stein, and prove that the lower non-luminous portion of a gas-flame is much more transparent than the upper luminous portion, and that it is almost impossible to distinguish an object when viewed through several layers of such flame, the same object being seen when viewed through a single laver. The eye becomes dazzled by the light of the flame, and so incapable of sharply distinguishing objects which emit lesser degrees of light. Tested in the sunlight, all non-luminous or slightly luminous flames appear exceedingly transparent, luminous flames appear transparent only when viewed in thin layers, and smoky flames only when viewed in small masses.

Frankland asks how a luminous flame can be so transparent as it is if it contain particles of solid carbon. A simple experiment suffices to show that the smoky portion of the flame of turpentine, which Frankland must admit contains solid particles, is as transparent as the flame itself. The presence of solid particles but very slightly decreases the transparency of a thick layer of flame. The spaces between the solid particles are comparatively large, and the particles are also in a state of rapid motion; a continuous image of any body placed behind the flame is therefore communicated to the eye, as is the case when one looks at an object behind a swiftly rotating spoked wheel.

In examining some of these luminous flames in sunlight, it occurred to me that if they really contain solid matter, they should throw a shadow on a white screen placed behind them. The flame of a candle I found experimentally does cast such a shadow as is depicted in fig. 3 ; the shadow extends as far as the luminous flame-mantle. The blue portion of the flame close to the wick, as also the upper blue portion, casts no 2 B 2 
shadow; as the luminous mantle only attains the necessary solidity at some distance above the wick, a space is seen to intervene between the wick and the shadow; it is only the sides of the lower part of the luminous mantle (through which the sun's rays travel obliquely) that are capable of casting a shadow ; hence the -shaped form of the lower boundaryline of the shadow. Streaks of varying clearness show themselves throughout the upper parts of the image of the flame; these are evidently due to the passage of the light through layers of flame of varying densities caused by the differences in temperature of the products of combustion. Fig. 4 represents the shadow thrown by the flame of turpentine; the soot which appears to the eye in the upper portions of this flame is shown by the shadow to extend continuously almost to the wick.

It seemed to me necessary to test this new method of examining flames by the shadows which they cast in sunlight, by comparing together as many and as various flames as possible. Having proved to myself that the flame of pure hydrogen casts no shadow upon a white screen, but only the image of a few more or less dense streaks (fig. 5), I caused the gas to traverse an apparatus in which it should become laden with solid material (zinc oxide, magnesia, \&c.) before ignition. The flame now in each case cast a most distinct shadow. When finely divided carbon (soot from a turpentine-flame) was thrown into the flame of hydrogen, the flame became strongly luminous, and a shadow at once appeared on the screen.

As an example of a flame undoubtedly containing solid matter, I employed hydrogen laden with the vapour of chromyl dichloride $\left(\mathrm{CrO}_{2} \mathrm{Cl}_{2}\right)$. During the combustion of this flame chromic oxide is produced; this oxide is not converted within the flame into a non-solid substance or substances, as is partly the case with the carbon liberated in the flames of hydrocarbonaceous bodies. Fig. 6 represents the shadow cast by the flame of hydrogen laden with the vapour of chromyl dichloride; it is very similar to the shadow of the turpentine-flame.

The observation of the shadow thrown on the screen by a flame serves as a means for determining the action which is taking place within that flame. Spontaneously-inflammable silicon hydride throws a very distinct shadow, resembling that cast by a turpentine-flame. The gas is evidently decomposed with the production of solid silicon, which is again oxidized in the outer portions of the flame to silica, itself also a non-volatile solid.

The flame of hydrogen containing the vapour of osmic acid 
is found by the shadow test to contain solid matter; this doubtless consists of finely divided osmium.

Kersten states that several metallic chlorides, when brought in the state of solution into the flame of a Bunsen's lamp, cause that flame to become luminous. Those chlorides which thus produce luminosity are, according to Kersten, ferrous, cuprous, palladium, and gold chlorides; chlorides of zinc, antimony, platinum, silver, tin, mercury, as also chlorides of the alkali-metals and alkaline earths, do not, according to the same authority, cause the Bunsen flame to become luminous*.

These chlorides may cause luminosity by deposition of metal, or by decomposition of hydrocarbons by means of chlorine, and consequent production of carbon within the flame.

In my experiments I substituted the flame of hydrogen or carbon monoxide for that of the Bunsen lamp. I found that the introduction of iron, platinum, and copper chlorides caused these flames to become luminous. The metallic chlorides were used in the solid state, as I found that the few drops of solution which could be introduced into the flame on a platinum wire spirted very much, and contained an extremely small quantity of solid matter. The following Table presents the results of the examination of a series of metallic chlorides and of other salts.

\section{Non-luminous Flames}

Became luminous by the introduetion of:-

Platinum chloride $\ldots \ldots \ldots$.

Iron chloride $\ldots \ldots \ldots \ldots \ldots$,

Chromyl dichloride. ......

Osmic acid ............

Ammonium dichromate....

Silver nitrate (blue colour).

Stannous and stannic chlorides (blue colour).......

Manganous chloride (greenish colour) .............

Gold chloride (greenish colour) ..............

Cuprous and cupric chlorides (blue and green colours)...
Did not become luminous by the on introduction of:-

Lead chloride, (blue-white) to

Lead nitrate $\}$ colour).... T

Alkali and alkaline-earth salts ................

Boric acid (green colour) $\ldots$...

\section{尺} yellow colour).......... Antimony and its salts (whitish colour) ........ Mercuric chloride. Magnesium chloride.

Silver chloride.
Arsenic and it salto (white-

If the substances which are brought into the flame be nonvolatile at the temperature of the flame, yellowish-white light is alone emitted, the flame appears very luminous and affords

* In one of Davy's early papers I find an experiment described in which cupric chloride was used to bring about luminosity in a flame. 
a continuous spectrum. If the metal or oxide which is separated in the flame be partially volatilized, one part of it may remain in the solid form and so impart luminosity to the flame, while another portion may become gaseous and so impart colour to the flame. The luminous portions of such flames show a continuous, the coloured portions a line-spectrum.

Those substances which do not cause a non-luminous flame to become luminous may also be subdivided into those (salts of lead, of alkalies, alkaline earths, except magnesia, \&c.) which are easily volatilized and therefore colour the flame while affording line-spectra, those (arsenic and antimony compounds) which afford continuous spectra while also imparting a colour to the flame, those (mercuric chloride) which volatilize almost immediately without producing any noticeable effect upon the flame, and, lastly, those (magnesium and silver chlorides) which, although undergoing decomposition with the production of solid matter, nevertheless do not cause luminosity because the solids produced are not carried into the flame. The metal or oxide which is separated in the various experiments may be obtained by bringing a porcelain basin into the flame.

If it be true that the luminosity is due in the foregoing $e x-$ periments to solid matter separated within the flame while the colour is caused by heated vapours, we should expect to find the luminous flames casting shadows upon a white background when viewed in sunlight, while the coloured flames would cast no shdaows.

Experiment has proved the correctness of this expectation in every case.

The flames of burning magnesiumi and of coal-gas containing oxygen and metallic zinc both cast very distinct shadows; these flames contain magnesium and zinc oxides respectively, substances which remain solid at high temperatures.

From these experiments I think we may draw the following inference:-

Luminous flames which owe their luminosity to the presence of finely divided solid matter produce characteristic shadows when viewed in sunlight.

But is the converse of this true? Do luminous flames which produce shadows in sunlight owe their luminosity to the presence of solid matter?

To this question, in the absence of experimental evidence, I should answer no; for it is possible that luminous flames consisting only of heated gases may, when riewed in sunlight, cause an appearance similar to that of a true shadow. We know that the electric light, when passed through 
burning hydrogen which has been coloured yellow by the presence of sodium chloride, is partly absorbed thereby, and that the light which passes on shows a dark absorption. band. So also sunlight is more or less absorbed when passed through various glowing gases. As sunlight already shows dark lines corresponding with light spectral lines of sodium, barium, calcium, copper, \&c., it is not to be expected that flames coloured by these metals in the gaseous state should cause absorption of any part of the sun's rays. But it is otherwise with colourless luminous flames. Such flames absorb portions of the rays of almost every part of the solar spectrum. These flames must therefore cause a shadow-like appearance on the screen, unless the absorption be too trifling to allow of our eye detecting the relatively dark spaces. That the eye is unable to detect any dark spaces, I have proved experimentally. I have not succeeded in obtaining any flame owing its luminosity only to strongly heated gases which is capable of throwing an appreciable shadow on a white screen when viewed in sunlight. That the flames of carbon monoxide, sulphur, selenium, sulphuretted hydrogen, and carbon disulphide should cause no shadow (although affording continuous spectra) may perhaps be chiefly due to the small quantity of light emitted by them. But it was also found that the exceedingly luminous flames of arsenic, phosphorus, and phosphuretted hydrogen burning in oxygen, as also of oxygen and nitric oxide in carbon disulphide, produced no appearance of a shadow on the white screen. The absorption caused by these flames upon the sunlight was therefore too small to admit of detection by the unaided eye. On account of their volatility, arsenious and phosphoric oxides must be present in the gaseous condition in the flames produced by burning arsenic and phosphorus in oxygen. These flames are therefore transparent: it is only at some distance above the flames that the products of combustion assume the solid form; the white smoke so produced casts a deep shadow on the screen.

From an extended series of observations, we conclude that luminous flames consisting only of gases and vapours are incapable of producing an appreciable shadow when viewed in sunlight; lighter and darker streaks, due to the varying densities of the vapours, of course appear in the images of these flames thrown on the screen.

The appearance of a shadow is therefore proof of the presence of suspended solid matter in the flame causing the shadow.

It follows from this that the luminous flames of hydrocarbons contain solid matter, inasmuch as they produce very sensible shadows. It is evident that this solid matter can be 
nothing else than carbon. The shadow test therefore supplies us with a means of detecting the presence of solid carbon in such flames.

Some time after writing the foregoing pages I noticed a memoir by G. A. Hirn entitled "Sur les propriétés optiques de la flamme des corps en combustion, et sur la température du soleil "*. In this paper Hirn describes the behaviour of various flames when viewed in sunlight; his conclusions, however, are directly opposed to those which I have deduced.

Hirn starts with the assumption that luminous hydrocarbonflames contain solid carbon, luminous phosphoras-flame contains solid pentoxide of phosphorus \&c.- that the transparency of these flames is due to a change, brought about by the high temperature, in the optical properties of the solid particles contained in the flames, whereby these particles become transparent and incapable of reflecting light.

I shall endeavour to show that Hirn's conclusions are invalid. In his preliminary assumption Hirn takes no notice of Knapp's experiments, which show that the decrease in luminosity of hydrocarbon-flames, brought about by admitting air, is not to be traced to oxidation of the carbon, inasmuch as pure nitrogen causes the same result $\uparrow$. Frankland's supposition that the luminosity of hydrocarbon-flames is not due to the presence of solid carbon had been disputed by no one when Hirn's paper appeared. Frankland had shown, five years previous to the appearance of Hirn's paper, that phosphorus pentoxide is volatilized at temperatures lower than that of the flame of phosphorus burning in oxygen, and that therefore the luminosity of this flame cannot be due to the presence of solid phosphorus pentoxide.

Of Hirn's assumptions-that the luminosity of hydrocarbonflames is due to the presence of solid carbon, and that the luminosity of phosphorus burning in oxygen is due to the presence of solid phosphorus pentoxide - the first was unproved at the time he wrote, and the second is untrue.

Light reflected from a solid body is known to be polarized. Hirn found the light from ordinary hydrocarbon-flames, as also the light from burning phosphorus, to be non-polarized; he also failed to detect evidence of polarization in the light coming from the flame of the blast-furnace. He found, however, that the white smoke rising from the phosphorus-flame emitted polarized light, as did also the smoke coming from the blast-furnace when the furnace-doors were opened. He concluded that the flame of the furnace owes its brilliancy to the

* Ann. Chim. Phys. [4] rol. xxx. p. 319.

† Journ. Pract. Chem. [2] vol. i. p. 425. 
presence of those metallic salts which appear in the solid form when the doors are opened. This conclusion tacitly assumes the presence of solid matter in the flame of the blast-furnace. Hirn does not appear to have examined the spectrum of this flame; and, so far as our knowledge extends, the contrary assumption to that made by Hirn appears quite as credible as his.

Hirn thus assumes that the light from a flame which contains solid matter must show evidence of polarization, and that the absence of polarized light is only to be accounted for by supposing that the solid particles become optically altered at a very high temperature, and lose their power of reflecting light. It appears to me that the facts observed by Hirn would be much better explained by regarding the absence of polarization as proof of the absence of solid particles in the flame. This explanation would apply to the phosphorusflame, and perhaps also to the flame from the blast-furnace. I have, however, convinced myself by experiment that the non-recognition of polarized rays in the light coming from a flame is not proof of the absence of solid matter in that flame.

The amorphous carbon present in the luminous flames of ordinary combustible hydrocarbons reflects almost no light; these flames show no traces of polarized light when examined by means of the polariscope. The light from many other non-homogeneous bodies is also devoid of noticeable polarized rays. We cannot, therefore, assume that the light emitted by a flame containing a small quantity of finely divided solid matter must show such a number of polarized rays as shall be recognizable by the polariscope. Hydrogen-flames, rendered luminous by the presence of platinum chloride, osmic acid, ammonium chromate, ferric and cupric chlorides, \&c., showed no traces of polarized light when examined by means of Arago's and Savart's polariscopes ; yet these flames certainly contained solid matter.

The flame of hydrogen containing chromyl dichloride also failed to show polarized light: the smoke of this flame, and also of the turpentine-flame, when examined in sunlight, afforded evidence of polarization. I am inclined to trace the polarizing action of the smoke in these cases to the presence of condensed water, tarry matter, hydrochloric acid, \&c., which substances would be present as gases in the flame itself.

I cannot, therefore, regard the non-detection of polarized light as proof of the absence of solid matter in flame; much less can I agree with Hirn's statement, that "the solid particles lose their power of reflecting light at a white heat." 
In the second section of his paper Hirn notices a statement made by Offret*, who, reasoning from Arago's observation that the luminous effect of a flat gas-flame, as measured by the photometer, is the same whether the broad or narrow end be turned towards the instrument, concludes that the luminous gas-flame is completely transparent. Hirn shows from his own observations that Arago's statement is not quite correct, and that the broad side of the flame always emits a little more light (about one fifth more) than the narrow side of the flame. Offret mentions the well-known fict that the light from an oil-lamp or candle, when thrown through the electric or lime light, casts a shadow on the opposite wall : he, and Hirn also, regards this phenomenon as due to refraction caused by the heated, and therefore thin, layers of gas.

I have, however, shown that luminous flames throw true shadows when carefully examined, and that these shadows are independent of the darker and lighter bands caused by refraction.

In section 3 of his paper Hirn examines the transparency of the flame of petroleum-lamps for light enitted from flames of the same kind. An old-fashioned shadow photometer was employed. A system of eight large lamps placed one behind another, served as the source of light. Hirn's observations and calculations led him to the conclusion that the light from such lamps suffers a greater diminution by passing through the hot gaseous products of combustion, than by passing through the luminous flames themselves. The method of calculation adopted by Hirn appears to me to be altogether erroneous. By applying what $I$ must regard as a more rational method of interpretation to Hirn's results, I find that there is a decided decrease in luminosity brought about by the action of the separated carbon upon the light passing through the flames of these lamps, over and above that occasioned by refraction in passing through the heated layers of gas $\dagger$.

Hirn discusses the transparency of flames for light from foreign sources in the fourth section of his paper: he again unfortunately chooses the flame of burning phosphorus. From the fact that the flame of burning phosphorus causes no shadow, while the smoke, so soon as it becomes visible to the eye, does cast a shadow, Hirn concludes that the solid phosphorus pentoxide suspended in the flame is transparent; we

* Essay presented to the Société d'Agriculture, Douai.

+ [The original paper contains Hirn's numbers, with a description of his, and of Heumann's method of calculation: the latter method is certainly much the more rational. Hirn's photometric process is also shown by his own results to be rery faulty.-M. M. P. M.] 
have long known, however, that the oxide does not exist in the solid form in the flame.

I have noticed a faint shadow cast by the flame of phosphorus burning in air; but as this shadow disappears on substituting oxygen for air, I conclude that in the former combustion the temperature is scarcely high enough to ensure the complete conversion of solid into gaseous matter.

Hirn further says that the flame of a petroleum-lamp throws no shadow on a. screen when viewed in sunlight, but that when the flame is rendered smoky the smoke causes a most marked shadow. From the detailed description of Hirn's experiment, it is evident to me that he placed the screen at too great a distance from the flame. He also obtained no distinct shadow when the sunlight was sent, by means of a looking-glass, through a series of eight petroleum-flames. On account of the interference between the flames, and also on account of their distance from the screen, this result is not. to be wondered at*.

The petroleum-flame employed by Hirn was surrounded by a glass cylinder, which seriously interfered with the distinctness of the shadow produced.

It is not possible, by removing the screen further and further from the flame, to obtain a clearly defined shadow much exceeding in size the dimensions of the flame itself. If, however, the sunlight be collected by a convex lens, and be thrown on the flame, a large and well-defined shadow may be obtained; the eye is also less fatigued by the glare of the white screen.

Fig. 7 represents the shadow thrown by a non-smoky coalgas flame, burning at the orifice of a tube 7 millims. in width : fig. 8 represents the appearance on the screen after removing the luminosity of this flame by admission of carbon dioxide. If the flame was rendered wholly or partially non-luminous by the introduction of a piece of metal, the shadow wholly or partially disappeared : emission of light and production of shadow are therefore closely related to one another.

The flat flame of a very small bat's-wing burner produces no shadow; but if the flame be turned edgeways towards the screen, a small but distinctly perceptible shadow is produced. In the first instance the layer cf luminous flame is too thin to cause the production of a shadow ; if an ordinary-sized burner

* Hirn remarks that the smoke arising from a petroleum-flame appeared white when illuminated in a dark room. This is, I think, due to ruflection of light from the smoke, chiefly from the particles of water, tarry matter, \&c., the black smoke being itself nearly invisible against the dark background. 
be employed a shadow is obtained. This shadow is most distinct towards the outer edges of the flame, where the thickness of luminous matter attains a maximum.

Fig. 9 represents the shadow thrown by the flame of an ordinary burner.

Fig. 10 represents the shadow produced by directing the small flame against the screen. Figs. 11 and 12 show the forms of shadows produced by adding an excess of benzol vapour to the gas (coal-gas or hydrogen) issuing from ordinary burners. Similar appearances result with the flame of hydrogen rendered luminous by admission of chromyl dichloride. These experiments show that the shadows increase in intensity as the thickness of the lnminous layer increases, or, in other words, that the intensity of the shadow is dependent upon the number of carbon particles which prevent the passage of the sun's rays through the flame.

Hirn blew lycopodium powder into a flame; before the powder was completely ignited the flame produced a shadow; after complete ignition, however, no true shadow was obtained. $\mathrm{I}$ have carefully repeated this experiment, and find that a flame containing a considerable quantity of lycopodium powder produces a marked shadow. Hirn probably used too little of the powder, or placed his screen at too great a distance from the flame. It is of course to be expected that the shadow produced by a flame in which the lycopodium powder is undergoing thorough combustion should be less marked than that formed by a flame which contains unburned lycopodium : in the former case the shadow is due to the presence of separated carbon only.

The sole experiment of Hirn which is capable of interpretation in terms of his theory only, is that in which the light of burning magnesium wire was passed through the flames of eight petroleum-lamps : the increase in the light-effect of these eight flames was equal to the total light-effect of the magnesium when burned by itself. But Hirn's previous experiments showed that the light from two petroleum-lamps loses 39.9 per cent.* when passed through six other similar flames ; it is scarcely possible therefore that the light of burning magnesium could suffer no diminution in luminosity when passed through eight petroleum-flames. Hirn's photometric process is, as his own results show, altogether untrustworthy.

Hirn says that the flame of the blast-furnace is completely transparent: this may be so. His conclusion, that this flame contains solid matter, but that this solid matter is optically

* Calculated according to my method. 
changed at the high temperature of the flame, is, I think, based upon no solid foundation of fact.

Hirn describes experiments with coloured flames (Bengal fire, \&c.). His conclusion, that these flames contain much solid matter, although they cast no shadow, is evidently incorrect. The colour is, of course, due to vapour, not to solid matter.

Lastly, Hirn regards the petroleum-flamo as diathermanous; but even admitting that this flame allows more or less the passage through it of heat-rays (a problem which I am not in a condition to examine experimentally), this would not contradict the demonstrated fact of the presence of solid carbon in ordinary luminous flames.

I think I have now shown that Hirn's hypothesis, viz. that solid bodies when raised to a white heat lose their power of reflecting light and become transparent, is without experimental support, and therefore cannot be maintained.

In the attempt to discover the causes of the luminosity of flame, it is necessary that the observer should be acquainted with the physical as well as with the chemical data which he will be required to examine. A want of this twofold knowledge has already led many to view the phenomena of luminous flames either from the purely physical, or from the purely chemical standpoint; in either case the result has been disastrous.

In conclusion, I would once more draw attention to the observations of $W$. Stein. If soot be present in the form of vapour in luminons flames, the application of a high temperature, after condensation, should cause it to again assume the gaseous form; but this is not the case. Further, the soot deposited from a coal-gas flame does not contain more than 0.9 per cent. of hydrogen.

I would now gather together the

\section{Proofs of the Presence of Solid Carlon in Luminous Hydro- carbon-Flames.}

(1) Chlorine causes an increase in the luminosity of feeblyluminous, or non-luminous, hydrocarbon-flames. Inasmuch as chlorine decomposes hydrocarbons at a red heat, with separation of carbon, it follows that the increased luminosity is due to the production of solid carbon particles.

(2) A small rod held in the luminous flame becomes rapidly covered on its lower surface (the surface opposed to the issuing gas) with a deposit of soot. The solid soot is evidently driven against the rod. If the soot were present as vapour in the luminous flame, its deposition would be due to a lowering of 


\section{Messrs. Wanklyn and Cooper on the Determination}

the flame-temperature, and would therefore take place on all sides of the rod.

(3) A strongly heated surface also becomes covered with a deposit of soot. This would not be possible if the deposit were the result of the cooling action of the surface upon the flame.

(4) The carbon particles present in the luminots flame become visible when the flame is caused to rush against another flame or against a heated surface. The separated particles are rolled together into larger masses, so that the luminous mantle becomes filled with numerous glowing points. The soot of such a flame is very coarse-grained.

(5) The luminous mantle of a flame is not altogether transparent: the thicker the flame-layer and the greater the number of solid particles contained therein, the less transparent does it become. The transparency of a luminous flame is no greater than that of the (approirimately) equally thick stratum of soot which rises from the flame of burning turpentine, and which is universally allowed to contain many solid carbon particles. The luminous flame of hydrogen, containing solid chromic oxide, is as transparent as the hydrocarbonfiame.

(6) Those flames which undoultedly oue their luminosity to the presence of finely divided solid matter, produce characteristic shadows when viewed in sunlight. The only luminous flames which do not produce true shadows are those which consist of glowing vapours and gases. Luminous hydrocarbonflames produce strongly marked shadows in sunlight; these flames therefore contain finely divided solid matter. That this solid matter can be nothing but carbon is evident from the fact that other substances, capable of remaining solid at the temperature of these flames, are absent.

These proofs are, I think, sufficient to convince every one that the luminous flames of hydrocarbons actually contain solid carbon particles.

Darmstadt, Chemisches Laboratorium des Polytechnicums.

LI. On a Method of determining the Amount of Proteine Compounds in Vegetable Sulstances. By J. ALFRED WankLYN, Corresponding Member of the Royal Bavarian Academy of Sciences, and W. J. COOPER*

THE physiological doctrine that the animal does not produce proteine compounds, but simply transforms those proteine substances which it has taken in as food, lends great

\footnotetext{
* Communicated by the Authors.
} 